\title{
Reply to "Expansion of Clonal Complex 258 KPC-2-Producing Klebsiella pneumoniae in Latin American Hospitals: Report of the SENTRY Antimicrobial Surveillance Program"
}

W e acknowledge the letter and comments from Castanheira et al. (3) on our manuscript describing dissemination of the $b l a_{\mathrm{KPC}-2}$ gene by the spread of different Klebsiella pneumoniae clones and the diversity of plasmids among AmpC chromosomal $\beta$-lactamase-producing Enterobacteriaceae species in Brazil. Recruitment of carbapenem-resistant isolates from six hospitals in two Brazilian areas (southeast, Sao Paulo and Rio de Janeiro states, and south, Rio Grande do Sul state) and searching for clonality and resistance mechanisms led us to describe dissemination of $K$. pneumoniae high-risk clones in this country, including sequence type 258 (ST258), ST11, and ST437, coupled with KPC-2 carbapenemase (1). The presence of Tn4401 variants associated with plasmids from different incompatibility groups (IncFII, IncN , and IncL/M) was also found.

A similar complex situation involving different STs belonging to K. pneumoniae clonal complex 258 (CC258) (ST11, ST258, ST340 and ST437) in Brasilia and Sao Paulo, Brazil, as well as in Buenos Aires, Argentina, was also communicated by Castanheira et al. (3). These observations confirm our findings and those from other authors of penetration and expansion of CC258 strains carrying $b l a_{\mathrm{KPC}-2}$ in Latin American hospitals similar to that occurring in North America, Europe, and Asia (1, 4-6). It is important to note that unlike our study, Castanheira et al. (3) were able to offer prevalence rates as their isolates are part of the SENTRY Antimicrobial Surveillance Program, which every year collects isolates from different continents. The presence of carbapenem resistance in the Enterobacteriaceae isolates submitted by Latin America participant centers in 2010 was $4.2 \%$ overall, with $3.3 \%$ overall being KPC-2 producers, most of them (84\%) K. pneumoniae isolates.

Apart from these comments, we would like to stress the relevance of the work done by antimicrobial resistance surveillance studies, such as that performed by the SENTRY program. This international program complements local studies and monitors resistance trends in a systematic manner. The SENTRY study offers not only compiled susceptibility testing data (i.e., MIC values) of different bacterial isolates against several antimicrobial agents but also the possibility of detecting and characterizing emerging resistance mechanisms.

From an epidemiological point of view and with a perspective of public health (2), it is particularly relevant to maintain surveillance studies in a scenario of decreasing funding for these programs at the governmental level. This decrease contrasts with the increasing prevalence of antimicrobial resistance worldwide, rapid dissemination of emerging resistance mechanisms, and classical recommendation of the World Health Organization (WHO) on surveillance programs as part of actions for containment of resistance (http://www.who.int /drugresistance/WHO_Global_Strategy_English.pdf). More recently, the Transatlantic Taskforce on Antimicrobial Resis- tance (TATFAR) initiative established to enhance the mutual understanding of United States and European Union activities and programs relevant to the antimicrobial resistance issues has highlighted antimicrobial resistance surveillance programs as an opportunity for collaboration. The aim of this collaboration is to collect relevant information at the patient level as well as to characterize the resistant bacterial isolates and the corresponding resistance mechanisms (http://ecdc.europa.eu/en /activities/diseaseprogrammes/tatfar/pages/index.aspx?Master Page $=1)$. TATFAR recognizes surveillance studies as important tools to identify populations where drug-resistant reservoirs and infections occur and to assess the effectiveness of infection control interventions to prevent the dissemination of the bacteria to new individuals and populations. The dissemination of $b l a_{\mathrm{KPC}-2}$ associated with high-risk clones, such as those represented in CC258, underscores the importance of epidemiological alerts and implementation of containment measures.

\section{ACKNOWLEDGMENTS}

We thank participants in our study (R. Martinez, F. BellissimoRodrigues, A. Basile-Filho, M. A. Evaristo, P. F. Del Peloso, V. B. Ribeiro, A. L. Barth, M. C. Paula, J. C. Ferreira, J. M. Longo, and E. C. Climaco) for laboratory support and collecting carbapenem-resistant isolates.

\section{REFERENCES}

1. Andrade LN, et al. 2011. Dissemination of blaKPC-2 by the spread of Klebsiella pneumoniae clonal complex 258 clones (ST258, ST11, ST437) and plasmids (IncFII, IncN, IncL/M) among Enterobacteriaceae species in Brazil. Antimicrob. Agents Chemother. 55:3579-3583.

2. Baquero F, Cantón R, Cornaglia G. 2010. Public health microbiology, a challenge for Europe. Clin. Microbiol. Infect. 16:123-125.

3. Castanheria M, Costello AJ, Deshpande LM, Jones RN. 2012. Expansion of clonal clomplex 258 KPC-2-producing Klebsiella pneumoniae in Latin American Hospitals: report of the SENTRY Antimicrobial Surveillance Program. Antimicrob. Agents Chemother. 56:1668-1669.

4. Cuzon G, et al. 2010. Worldwide diversity of Klebsiella pneumoniae that produce beta-lactamase $b l a_{\mathrm{KPC}-2}$ gene. Emerg. Infect. Dis. 16:13491356.

Address correspondence to R. Cantón, rcanton.hrc@salud.madrid.org.

This is a response to a letter by Castanheira et al. (doi:10.1128/AAC05942-11) Copyright $\odot$ 2012, American Society for Microbiology. All Rights Reserved. doi:10.1128/AAC.00041-12 
5. Gomez SA, et al. 2011. Clonal dissemination of 97 Klebsiella pneumoniae ST258 harbouring KPC-2 in Argentina. Clin. Microbiol. Infect. 17:1520 1524.
6. Woodford N, Turton JF, Livermore DM. 2011. Multiresistant Gramnegative bacteria: the role of high-risk clones in the dissemination of antibiotic resistance. FEMS Microbiol. Rev. 35:736-755.

\section{Teresa M. Coque}

Servicio de Microbiología

Hospital Universitario Ramón y Cajal

Madrid, Spain

\section{Leonardo Neves Andrade}

Ana Lucia da Costa Darini

Faculdade de Ciências Farmacêuticas de Ribeirão Preto

Universidade de São Paulo

Ribeirao Preto, Brazil

\section{Tania Curiao}

Fernando Baquero

\section{Rafael Cantón}

Servicio de Microbiología

Hospital Universitario Ramón y Cajal

Madrid, Spain 